\title{
A survey of basic resuscitation knowledge among resident paediatricians
}

\author{
P W Buss, M McCabe, R J Evans, A Davies, H Jenkins
}

\begin{abstract}
A telephone questionnaire was undertaken to evaluate the knowledge of resident paediatricians on the subject of the basic resuscitation of the acutely sick child. The questionnaire was targeted at 88 resident paediatricians in hospitals accepting paediatric emergencies in four health regions. Outcome was measured as a correct response to questions based on several emergency scenarios and on the confidence expressed of basic resuscitation knowledge.

The subject of emergency management of the child with a compromised upper airway was poorly answered with $40 / 73(55 \%)$ resident paediatricians suggesting an incorrect endotracheal tube size for an $\mathbf{8}$ year old child. Fluid management was also deemed unsatisfactory with only 36/73 (49\%) providing adequate transfusion secondary to haemorrhagic shock. In addition only $19 / 73(26 \%)$ mentioned the intraosseous route as a means of obtaining vascular access in a child in extremis.

Confidence of the knowledge of basic resuscitation of children was low among resident paediatricians with only $30 / 73(41 \%)$ expressing confidence and 69/73 (94\%) expressing a desire for more formal training in paediatric resuscitation.

Resident paediatricians are usually the key personnel in the management of very sick children. This survey demonstrates a low level of basic resuscitation knowledge among resident paediatricians of all grades that must be remedied at a local and national level.
\end{abstract}

(Arch Dis Child 1993;68:75-8)

In the early 1980s the ability of house officers to perform adequate cardiopulmonary resuscitation was questioned. ${ }^{12}$ As a result of the work done and recommendations made by a working party of the Royal College of Physicians, ${ }^{3}$ training programmes were implemented to improve general resuscitative care and knowledge among this group. Recent work has suggested that these measures have served to improve knowledge of resuscitation among preregistration house officers. ${ }^{4}$ Very little work has been done to assess paediatricians' confidence and knowledge in dealing with the resuscitation of extremely sick children in the UK. Few can doubt that paediatric emergency resuscitation must represent one of the most stressful events in the workplace of a junior doctor. However no structured training programme for dealing with such emergencies exists, to date, in the UK. There are also no specific guidelines for units to meet regarding the provision of structured training to front line paediatricians. It was recognised by Zideman in 1986 that structured training for paediatricians should, but does not, exist on a national level for both community and hospital based paediatricians. ${ }^{5}$

Oakley in 1988 demonstrated, among a small number of paediatricians in a single unit, significant delay in decision making and also inaccuracy in estimation of drug dosage during cardiopulmonary arrest procedures. ${ }^{6}$ This resulted in the development of a chart for paediatricians to consult during resuscitation procedures. Recent work in America has suggested that many paediatric practitioners feel uneasy regarding their ability to cope in a number of emergency situations. ${ }^{7}$

We therefore assessed paediatricians' basic knowledge and confidence in the emergency situation by telephone questionnaire.

\section{Methods}

We attempted to contact, by telephone, a total of 88 resident paediatricians in 44 hospitals accepting acute paediatric admissions in four health regions (Wales, South West region, Wessex, and the West Midlands). This included paediatricians of all grades from senior house officer to senior registrar. On each occasion an attempt was made to contact the most senior resident paediatrician. A maximum of two paediatricians were targeted in each hospital.

Regions were selected for the presence of a single teaching unit with a similar number of district general hospitals accepting acute paediatric admissions. Consideration was given to regions of close proximity to Wales to reduce costs of the survey.

The main reason for choosing a telephone questionnaire was to simulate more closely an emergency clinical situation. A reasonable, but not inordinate, amount of time was made available for questions to be answered.

The interviewers were all experienced in the resuscitation of the acutely sick child and consisted of two paediatric registrars (PWB and $\mathrm{AD}$ ) and two senior registrars in accident and emergency medicine (MMc and RJE). Each interviewer was allocated one of the four regional health authorities. The telephone questionnaire consisted of two parts. The first set eight emergency scenarios (table 1 ) that required answers regarding their management and was to 
assess the basic resuscitation knowledge of the individuals. The second section (table 2) comprised general questions pertaining to the paediatricians' experience and training.

The correct answers on the management of the eight emergency scenarios were based on the $A B C$ of Resuscitation ${ }^{8}$ and $A B C$ of Major Trauma ${ }^{9}$ and an acceptable answer range was formulated (table 3) and provided a template for the

Table 1 A series of eight questions based on hypothetical emergency scenarios

\begin{tabular}{|c|c|}
\hline $\begin{array}{l}\text { Question } \\
\text { No }\end{array}$ & Individual emergency scenario \\
\hline (1) & $\begin{array}{l}\text { What size endotracheal tube would you use in a child } \\
\text { of . } \\
\text { (a) } 3 \text { months? } \\
\text { (b) } 4 \text { years? } \\
\text { (c) } 8 \text { years? }\end{array}$ \\
\hline (2) & $\begin{array}{l}\text { If necessary what dose } / \mathrm{kg} \text { of adrenaline would you } \\
\text { use in arrest procedures? }\end{array}$ \\
\hline (3) & $\begin{array}{l}\text { In a child who arrives following freshwater drowning, } \\
\text { asystolic with fixed dilated pupils but intubated at } \\
\text { scene by paramedics-for how long would you } \\
\text { consider resuscitation appropriate? }\end{array}$ \\
\hline (4) & $\begin{array}{l}\text { For resuscitation in class III haemorrhage }(30 \% \\
\text { blood loss) your fluid replacement would be with } \\
\text { (a) what fluid type? } \\
\text { (b) what fluid volume } / \mathrm{kg} / \text { unit time? }\end{array}$ \\
\hline (5) & $\begin{array}{l}\text { Do you know a formula for fluid replacement in } \\
\text { severe burns? }\end{array}$ \\
\hline (6) & $\begin{array}{l}\text { A severely shocked child where you are unable to } \\
\text { find } v \text { nous access. How would you gain vascular } \\
\text { access? }\end{array}$ \\
\hline (7) & $\begin{array}{l}\text { In a multiply injured child (road traffic accident) } \\
\text { what two } x \text { ray films would you most like to see? }\end{array}$ \\
\hline (8) & $\begin{array}{l}\text { In a child with acute severe airway obstruction } \\
\text { (epiglottitis) where bag and mask ventilation is } \\
\text { ineffective and intubation failed. How would you } \\
\text { gain airway access? }\end{array}$ \\
\hline
\end{tabular}

Table 2 Questions pertaining to the experience, training in paediatric resuscitation, and confidence of respondents in dealing with paediatric emergencies

\begin{tabular}{ll}
\hline $\begin{array}{l}\text { Question } \\
\text { No }\end{array}$ & General questions on experienceltraining \\
\hline$(9)$ & $\begin{array}{l}\text { What is your current NHS grade? } \\
\text { Do you have any postgraduate examinations relevant } \\
\text { to paediatric practice? }\end{array}$ \\
(10) & $\begin{array}{l}\text { Do you feel confident in your knowledge of } \\
\text { resuscitating acutely sick children? }\end{array}$ \\
(11) & $\begin{array}{l}\text { Have you received formal instruction in the } \\
\text { management of paediatric emergencies? If yes } \\
\text { where? }\end{array}$ \\
(12) & $\begin{array}{l}\text { Would you like structured training in the resuscita- } \\
\text { tion of the acutely sick child? If yes, what format? }\end{array}$ \\
&
\end{tabular}

interviewers with the defined standard. An answer in the correct range would credit the interviewee with a single mark (except for question 4 where half a mark was awarded to the two parts of the question). The allocation of marks was conducted by PWB using the template as described above. Each hospital was telephoned after 1800 hours and request made to speak with the senior resident paediatrician. A formal introduction to the questionnaire stressed the anonymity of the study and that the model answers could be obtained either following the questions or by sending them by post at a later date. We anticipated a few paediatricians asking to refer to their own notes or a book on their person. In fact three paediatricians responding requested this. For the purpose of this study this was declined but noted.

Each hospital was telephoned no more than twice and after this if we were unsuccessful in completing the questionnaire that hospital was not contacted again. Ethics committee approval was obtained before the commencement of the questionnaire.

\section{Results (table 4)}

In total 73 paediatricians of the 88 targeted agreed to be interviewed. The commonest reason for non-participation was that the person was too busy. Of the 73 there were $36(49 \%)$

Table 4 No (\%) with correct answers to questions on management of paediatric emergencies

\begin{tabular}{|c|c|c|}
\hline & Topic of question on emergency management & $\begin{array}{l}\text { No(\%) } \\
\text { correct }\end{array}$ \\
\hline (1) & $\begin{array}{l}\text { Endotracheal tube size required in arrest } \\
\text { (a) } 3 \text { months } \\
\text { (b) } 4 \text { years } \\
\text { (c) } 8 \text { years }\end{array}$ & $\begin{array}{l}60 / 73(82) \\
46 / 73(63) \\
33 / 73(45)\end{array}$ \\
\hline (2) & $\begin{array}{l}\text { Adrenaline dosage (intravenous/ } \\
\text { endotracheal) in arrest }\end{array}$ & $38 / 73(52)$ \\
\hline (3) & Resuscitation in drowned child & $20 / 73(27)$ \\
\hline (4) & $\begin{array}{l}\text { Hypovolaemic shock (blood loss) } \\
\text { (a) Fluid type } \\
\text { (b) Volume/kg/time }\end{array}$ & $\begin{array}{l}71 / 73(97) \\
36 / 73(49)\end{array}$ \\
\hline (5) & Hypovolaemic shock (burns) & $0 / 73$ \\
\hline (6) & $\begin{array}{l}\text { Access in shocked child (\% mentioning } \\
\text { intraosseous) }\end{array}$ & $19 / 73(26)$ \\
\hline (7) & $2 x$ ray films in mulitply injured child & $17 / 73(23)$ \\
\hline (8) & $\begin{array}{l}\text { Airway obstruction in epiglottitis . . . } \\
\text { management }\end{array}$ & $32 / 73(43)$ \\
\hline
\end{tabular}

Table 3 Answer template used to assess correctness of answers to questions $(1)-(8)$ in table 1

\begin{tabular}{|c|c|c|c|}
\hline $\begin{array}{l}\text { Question } \\
\text { No }\end{array}$ & $\begin{array}{l}\text { Acceptable } \\
\text { answer } \\
\text { range }\end{array}$ & $\begin{array}{l}\text { Unacceptable } \\
\text { answers }\end{array}$ & References \\
\hline (1) & $\left.\begin{array}{l}\text { (a) } 3-4.5 \mathrm{~mm} \\
\text { (b) } 4-5.5 \mathrm{~mm} \\
\text { (c) } 5-6.5 \mathrm{~mm}\end{array}\right\}$ Formula $=\frac{\text { Age }}{4}+4$ & & $5,6,11$ \\
\hline (2) & $0.1-0.5 \mathrm{ml} / \mathrm{kg}, 1 / 10000$ & & $6,8,11$ \\
\hline (3) & $\begin{array}{l}\text { Until warmer, hypothermia corrected, } \\
\text { consideration of temperature } \\
\text { correction }\end{array}$ & & 17 \\
\hline (4) & $\begin{array}{l}\text { (a) Colloid, plasma, blood, blood } \\
\text { products, expanders, } \\
\text { (b) } 15-30 \mathrm{ml} / \mathrm{kg} \text { in half hour }\end{array}$ & $\begin{array}{l}\text { Dextrose } \\
\text { Less than } 15 \mathrm{ml} / \mathrm{kg} \text { in half hour } \\
\text { More than } 50 \mathrm{ml} / \mathrm{kg} \text { in half hour }\end{array}$ & 8,12 \\
\hline (5) & Any verifiable formula & & 16 \\
\hline (6) & Intraosseus access mentioned & & $9,11,13,14$ \\
\hline (7) & Chest and cervical spine $x$ ray films & $\begin{array}{l}\text { Other } x \text { ray films/computed } \\
\text { tomogram }\end{array}$ & 9 \\
\hline (8) & Cricothyroidotomy & & $8,9,15$ \\
\hline
\end{tabular}


senior hours officerș and 37 (51\%) registrars/ senior registrars.

\section{(1) ENDOTRACHEAL TUBE SIZE}

When assessing endotracheal tube size a total of $60 / 73(82 \%)$ assessed a size within the acceptable range (of calculated size plus one size or minus two sizes) for a child of $\mathbf{4}$ months. For 4 years only $46 / 73(63 \%)$ were acceptable and for 8 years fewer than half $33 / 73(45 \%)$ were in the acceptable range.

\section{(2) ADRENALINE DOSAGE}

Only 38/73 (52\%) knew the dosage of adrenaline that they could acceptably use in children (acceptable range was $0.1-0.5 \mathrm{ml}$ of $1 / 10000$ per $\mathbf{k g}$ ). Those that were unacceptable either did not know or overestimated the dosage.

\section{(3) DROWNING}

Less than one third of those answering 20/73 (27\%) recognised the need for rewarming and therefore the need for more prolonged resuscitation of patients involved in freshwater drowning.

\section{(4) HYPOVOLAEMIC SHOCK}

Virtually all paediatricians 71/73(97\%) suggested the use of a colloid in the initial treatment of hypovolaemic shock (though normal saline was also allowed). Only 36/73 (49\%) actually gave an acceptable $15-30 \mathrm{ml} / \mathrm{kg}$ over half an hour as the volume and rate of infusion. Many did not have an idea of what volume they would give and others grossly overestimated the amount they would infuse.

\section{(5) BURNS/SHOCK}

No paediatrician was able to give us a burn's formula for fluid management in the severely burned child.

\section{(6) EMERGENCY VASCULAR ACCESS}

Only 19/73 (26\%) paediatricians mentioned the intraosseous route as a means of attaining vascular access in a child in extremis and then usually as third choice to central venous access and venous cut down. Central venous line and/ or cut down had only ever been performed by three of those questioned.

\section{(7) RADIOGRAPHY IN THE MULTIPLY INJURED CHILD}

Only $17 / 73$ (23\%) mentioned the combination of cervical spine and chest $x$ ray films in the multiply injured unconscious child. The skull $x$ ray film was thought most valuable by $41 / 73$ $(55 \%)$ of paediatricians.

\section{(8) UPPER AIRWAY COMPROMISE}

Only $32 / 73$ (43\%) suggested needle cricothyroidotomy. Most cited tracheostomy as the favoured means of attaining airway control.
(9)-(13) GENERAL QUESTIONS REGARDING CONFIDENCE AND TRAINING

In total only $30 / 73(41 \%)$ of senior resident paediatricians felt confident in managing paediatric emergencies. The average score for the confident group $(n=30)$ was 3.38 against a mean score of 2.5 for those with low confidence $(n=43)$. The mean score for the entire group was $2 \cdot 85$ out of a total of 8 .

Examination attainment did seem to be associated with a marginally better score (mean score with MRCP (UK) =3.65; mean score with no formal examinations $=2 \cdot 23$ ). The interpretation of this, however, is complicated by the greater general experience of those with the membership examination.

The mean score of 2.9 for paediatricians practising in units with an accident and emergency department was little different from that of paediatricians in units without (mean score $=2 \cdot 8$ ). There was almost universal requirement for more training involving lectures, courses, and videos etc: $69 / 73$ (94.5\%). Only $7 / 73(9 \%)$ had received prior training in paediatric emergency management and none of these while a paediatric resident.

In total 5/73 possessed the Diploma in Child Health and 7/73 possessed MRCP part 1 alone and 31/73 MRCP (UK). Therefore 30/73 most senior resident paediatricians possessed no formal postgraduate paediatric examinations.

\section{Discussion}

The survey reveals a lack of confidence among senior resident paediatricians in dealing with an emergency situation. Ninety four percent of this group expressed a desire for more training to cope with these uncommon but extremely stressful situations. Many complained at obtaining very little guidance before or during a post and claimed that if a paediatric emergency did arise that they would rely on members of other specialties (particularly anaesthetists) to help them through the crisis. This is a situation that must be remedied with structured training for all paediatric residents occurring at the commencement of a post.

The interpretation of results to individual questions is more difficult. There is little doubt in the authors' minds that a simple equation for endotracheal tube size in children and adrenaline dosage should be retained by every paediatrician in the UK. There is evidence suggesting that in the paediatric situation adequate skill, knowledge, and adeptness in intubation will save lives. In one study of 130 paediatric arrest situations $40 \%$ of ward arrests required expert airway management alone without cardiac compression. ${ }^{10}$ Therefore leaving this very basic information to a chart that might not be available at the tense scene of an arrest should not, we believe, be encouraged. The detail regarding further drug dosages on charts is indeed valuable and it is for these drugs (used in less than $25 \%$ of paediatric ward arrests ${ }^{10}$ ) that the chart is particularly useful.

It was interesting to note that only three paediatricians requested to refer to a book on their person. Although we recognise the validity 
of the request, we felt that physicians in this position would be required to know this basic information and so this request (for the purpose of assessing the knowledge of the interviewees) was declined. It was also felt that a great deal of information must be assimilated for both $\mathrm{MB}$ and MRCP examinations. The information requested of paediatricians in this study represented a tiny fraction compared with this.

It is apparent that, for children outside of the infant age group, knowledge of endotracheal tube diameter becomes increasingly poor leading to possible delay in intubation. Memorising a simple equation for this purpose is all that would be required. ${ }^{11}$ Adrenaline dosage (the most widely used drug in paediatric cardiopulmonary arrest) was not known by over $45 \%$ of those questioned. When looking at the shocked child all paediatricians suggested plasma re-expansion using colloid. However over $50 \%$ suggested an inadequate fluid regimen. ${ }^{12}$

The extremely worrying situation of a child in extremis with no peripheral route of vascular access led to the frequent answer of obtaining an anaesthetist or attempting a cut down, which is not only technically difficult but can take a great deal of valuable time even in skilled hands. ${ }^{13}$ Only $26 \%$ suggested that the intraosseous route could be used. This technically is an easy and reliable method of giving fluid and drugs with effective and rapid absorption. ${ }^{14} \mathrm{We}$ would not say that the answer of central venous cannulation, etc, was wrong but the trend of the answers suggests little practical thought of how the individual would indeed cope in this type of situation.

Management of the acutely obstructed airway showed that only $32 / 73(43 \%)$ suggested that they would perform a needle cricothyriodotomy, the preferred method for establishing airway access and control if bag and mask ventilation or intubation are unsuccessful. ${ }^{9}$ Most claimed they would perform an emergency tracheostomy. Although this approach may be theoretically feasible, this is a technically very demanding procedure and requires experience and skill. ${ }^{15}$

Answers to more technical emergency questions (such as knowledge of a formula for fluid management in burns ${ }^{16}$ ) showed a total lack of knowledge throughout all the grades. Kemp and Sibert demonstrated that adequate rewarming is vital in victims of freshwater drowning ${ }^{17}$; this represents the third commonest cause of death in accidents in children. ${ }^{18}$ This concept was only understood by $20 / 73(27 \%)$ of those questioned. Finally when faced with the most common serious situation of the child with multiple injuries as a result of a road traffic accident only $17 / 73$ (23\%) suggested a cervical spine and chest $x$ ray film as the most appropriate radiographs to be viewed. Many $41 / 73$ (55\%) asked for skull films or abdominal films initially.

The purpose of the questionnaire was to assess paediatricians' knowledge and confidence in dealing with extremely ill children. We chose the most senior resident paediatrician because it is they, like their adult counterparts, who will take the lead in a life threatening paediatric situation. It is, in fact, the paediatrician who is turned to for his/her expertise by other professionals.

The results of this survey suggest that the knowledge and training of basic resuscitation of these paediatricians is poor. We are aware of a paediatric advanced cardiac life support course being introduced in the UK this year. Until this becomes generally available the onus must be on senior paediatricians to recognise the need for adequate training of their junior staff at the commencement of their post.

1 Casey WF. Cardiopulmonary resuscitation a survey of standards amongst junior hospital doctors. $\mathcal{J} R$ Soc $M e d$ 1984;77:921-4.

2 Skinner DV, Casson A. Cardiopulmonary resuscitation skills of pre registration house officers. BMF 1985;290:1549-50.

3 Working Party of the Royal College of Physicians. Resuscitation from cardiopulmonary arrest. Training and organisation. $\mathcal{F} R$ Coll Physicians Lond 1987;21:181.

4 Morris F, Tordoff SG, Wallis D, Skinner DV. Cardiopulmonary resuscitation of preregistration house officers pulmonary resuscitation of preregista
five years on. $B M \mathcal{F} 1991 ; 302: 625-7$.

5 Zidemann D. Resuscitation of infants and children. $B M \mathcal{Y}$ 986;292:1584-7.

6 Oakley $P$. Inaccuracy and delay in decision making in paediatric resuscitation. BMf 1988;297:817-9.

7 Scwiech P, de Angelis C, Duggan AK. Preparedness o paediatricians to manage emergencies. Pediatrics 1991;88: 223-9.

8 Evans TK. $A B C$ of resuscitation. 2nd Ed. London: BMA 1991.

9 Skinner D, Driscoll P, Earlam R. $A B C$ of major trauma. London: BMA, 1991.

10 Ludwig S, Kettrick G, Parker M. Pediatric cardiopulmonary resuscitation. Clin Pediatr (Phila) 1984;23:71-6.

11 Rockney RM, Alarido AJ, Lewander WJ. Pediatric advanced life support (part 1) airway, circulation and intravascula access. Am Fam Physician 1991; Vol 43:1227.

12 American College of Surgeons-committee of trauma. Fluid resuscitation. Advanced trauma and life support manual-core course. Chicago: Chapman Hall, 1991:221.

13 Rhee KJ, Derlet RW, Beal SL. Rapid venous access using saphenous vein cutdown at the ankle. Am $\mathcal{F}$ Emerg Med 1989;7:263-6.

14 Orlowoski J, Porembka DT, Gallagher JM, Lokrem JD, VanLente F. Comparison of intraosseous, central venous and peripheral intravenous infusions of emergency drugs. Am $\mathrm{f}$ Dis Child 1990;144:112-7.

15 Kerr AG, Stell PM. Tracheostomy and decannulation. Scott Brown's otolaryngology. Vol 6. Sth Ed. London: Butterworth 1987:471-8.

16 Muir IFK, Barclay T. Fluid replacement-the use of formulae Burns and their treatment. London: Butterworths, 1987:26-8.

$17 \mathrm{Kemp} \mathrm{A,} \mathrm{Sibert} \mathrm{J.} \mathrm{Outcome} \mathrm{of} \mathrm{children} \mathrm{who} \mathrm{nearly} \mathrm{drown} \mathrm{in}$ British Isles study. BMF 1991;302:931-3.

18 Office of Population Censuses and Surveys. Death by cause 1988 registrations. OPCS Monitor 1989 (DH2). 